\title{
Working-class males and engagement with high school education
}

\section{Matthew Wilson}

Email: mattywilson1@hotmail.com

\begin{abstract}
This study explores working-class males' engagement with high school education as statistically this group are underachieving and the chosen city in the North-West of England has been highlighted as an area of particular concern. Questionnaires and semi-structured interviews were used in an attempt to establish which issues affected their engagement in school, allowing a critical insight into their attitudes towards education.

Findings indicate that there are a range of factors causing the educational disengagement of working-class boys in the city, ranging from deprivation to the content of the curriculum. The combination of causes is complex and varies between individuals, although the most common obstacle seems to be relationships between teachers and participants, with the issue of 'relate-ability' particularly evident.
\end{abstract}

Keywords: Class, Education, Male, Disengagement, Relate-ability, Deprivation, Inequality. 


\section{Introduction}

The purpose of the research upon which this paper is based was to investigate working-class males' engagement with high school education within a city located in the North-West of England, the rationale being that boys are underachieving in school nationally (Department for Education, 2014) and that there is 'significant underachievement of children from low-income families' (Ofsted, 2013, p5). The implications of this are significant and well documented. A lack of qualifications often result in limited labour market opportunities (Mclntosh \& Houghton, 2005), as well as an increased risk of becoming NEET (not in education, employment or training) (Ross, 2009). There are also links between educational disengagement and other negative outcomes such as drug and alcohol use (Beinart et al., 2002) and early parenthood (Hosie, 2007).

The motivation for this study derives from particular concerns about the future of working-class boys in this city, whilst also attempting to identify anything that may be unique to the city. This research is underpinned by my current role, which involves primarily working with young men who are overwhelmingly working-class and who have been referred to the service due to educational disengagement. The engagement of young people is crucial as recent legislation has raised the participation age, first to 17 by the year 2013, and then 18 by 2015 (Ross, 2009). Furthermore, the annual schools report by Ofsted in 2013 concluded that:

We have major concerns over secondary school provision in a number of local authority areas. It is unacceptable that in 13 local authorities, less than half of secondary students attend a good or outstanding school. Schools in these areas often have a range of underlying weaknesses, including high levels of exclusion and persistent absence (Ofsted, 2013, p6).

To put the research in context, this city has only 47 percent of pupils attending good or outstanding secondary schools (Ofsted, 2013). This means that High Schools in this particular area would rank in the bottom 10 out of the 150 local authorities in which inspections were carried out. With girls outperforming boys academically, it is argued that:

The gender gap arises mainly because of differences between boys and girls in language and literacy skills, reflected in differences in performance in English and other subjects which are literacy based (DfES, 2007, p5).

The same paper provides evidence of educational experiences in relation to gender, finding that 'boys account for 80 percent of permanent exclusions and three quarters of fixed-term exclusions' (DfES 2007, p6) and that 'these trends are apparent both from historical data and from English exam records going back 60 years' (DfES 2007, p5). So, this study aims to contribute to an ongoing debate, focussing on a city in North-West England. In that debate, Connelly (2006), identified the 'interactions effects model' which predicts that differences between girls and boys are not stable but vary across ethnic groups and/or social class. As a result, the gap in attainment is not related only to gender, but is also attributed to a combination of social class and gender or ethnicity and gender (Connelly, 2006). 


\section{Historical Perspective \& Policy}

Until the late-1980s, policymakers were concerned with the educational underachievement of girls. The early-1990s saw a major change as girls began to out-perform boys across all levels of the educational system (Browne \& Mitsos, 1998). However, it is important to recognise that focusing on gender alone and disregarding crucial factors such as social class is too simplistic, because not all boys underachieve (Ofsted, 2013). In 2009, a longitudinal study analysing disengagement from education among 14-16 year olds in England concluded that 'those most at risk of disengaging were white, male, and young people from more disadvantaged backgrounds' (Ross, 2009, p1).

A study conducted over fifty years ago (Jackson \& Marsden, 1962) exploring education and the working-class offers useful theory in terms of educational disengagement historically. The research is comparable to this study in terms of location, with both studies conducted in northern towns or cities. Due to deindustrialisation, young people are denied the opportunity to work alongside adults and 'where society does not permit the adolescent to assume a social role compatible with his physical and intellectual development, but keeps him dependent.... adult maturity is come by with more difficulty' (Jackson \& Marsden, 1966, p223-224). This study concludes that working-class young people have always disengaged from education although disengagement would not have been seen as a problem as manual jobs were more readily available in the 1960s. This sent the message that there was no need for boys to apply themselves in the classroom as it was not necessary to gain employment, resulting in a working-class culture not concerned with the promotion of boys' academic attainment (Burns \& Bracey, 2001). Educational disengagement among working-class boys was not highlighted as a concern and traditionally policymakers paid little attention to such matters. Undoubtedly, though, the school system has changed over the past half century with the majority of grammar schools being replaced by comprehensive schools and more recently academies and free schools in which Ofsted inspections often demand an improvement in educational standards, particularly in schools located in poorer, working-class neighbourhoods (DfE, 2014). Schools are then placed into league tables and forced to compete with one another. Consequently, schools may be tempted to focus time and resources on those most likely to achieve in an attempt to move up in this 'attainment league' (MacDonald \& Marsh, 2005). However, Hatcher explains that:

It should be emphasised that raising levels of pupil achievement does not necessarily entail reducing educational inequalities...standards can rise while the equality gap widens (Hatcher, 1997, p9).

A strong case can be made that one consequence of this school competition is that many working-class boys fail to receive the support they require to enable them to maximise their potential. This links with Paulo Freire's (1996) argument that the education system cannot work effectively if it fails to acknowledge the issues students bring with them to school, which may make education almost irrelevant to the individual's situation. Arguably, such processes could contribute towards workingclass boy's disillusionment and consequent disengagement with education. A study conducted into educational standards in Middlesborough (Simpson and Cieslik, 2000) supports the argument that academically-weaker pupils are neglected in 
favour of those deemed more likely to achieve academically; and as working-class boys are known to be underachieving nationally (DfE, 2014), arguably, they are, most likely to be affected.

The impact of government policy is worthy of consideration. The Home Office (1997) produced a paper with an emphasis on a zero-tolerance approach to anti-social behaviour, predominantly displayed by working-class males (Epstein et al., 1998). These negative portrayals suggest that they don't know how to behave and need to be controlled. It could be argued though that this group of young men may, in fact, respond by internalising these portrayals and, as thus behave accordingly. Although Frantz Fanon's (1961) ideas around consciousness were written concerning black people in particular, his theory may also be relevant to white working-class boys. Consequently, 'bad behaviour' would transfer into the classroom environment with those working-class males, targeted by the paper Bridging the Gap (SEU, 1999), becoming so disillusioned that they either avoid the system or rebel (Colley \& Hodkinson, 2001). New Labour (SEU, 1999) policy aimed at tackling social exclusion strongly implies that both the causes and solutions to educational disengagement lie within the school's system. It also suggests that this can be addressed whilst operating within the government's current guidelines. Colley \& Hodkinson (2001), however, argue that government policy fails to address the structural causes of disengagement, such as class. They raise the fundamental point that such approaches may not actually offer a solution, but may instead be part of the problem. It may then be that the current drive towards higher educational attainment forces institutions to exclude those who are unable to achieve the required standard, rather than creating a space for them to thrive.

There is also a suggestion that the cause of educational disengagement amongst boys is due to the feminisation of the education system, mainly concerned with the introduction of coursework with evidence concluding that coursework favours girls and exams favour boys (Browne \& Mitsos, 1998), but also concerning the workforce and content of the curriculum. However, middle-class boys still do well in education, therefore the difference may be explained in terms of the amount of encouragement young people get from parents surrounding coursework. The idea of a feminised curriculum does however, seem to ignore the fact that historically, there were significant barriers to girls' achievement in school (Epstein et al., 1998).

The 'discovery and discussion of alienated pupil sub-cultures has been a staple of educational ethnography for years' (MacDonald \& Marsh, 2005, p53). Furthermore, Willis (1977) argued that the reason for working class kids' disengagement with education was down to cultural resistance, or in other words, their refusal to conform to middle-class values, which are systematically entrenched within the education system - although whether working-class boys today actually have any comprehension or consciousness about middle-class values, is, at least, questionable. Brown (1987) challenges Willis' line of argument, by suggesting that working-class cultures and negative attitudes towards education differ locally and are shaped in the form of labelling by the varying school systems. Either way, there is arguably a culture among working-class boys to 'misbehave at school': it is simply not 'cool' to be clever (Epstein et al., 1998). If you are male and attend a state school located in an economically deprived area, the pressure to conform, the desire to 'fit in' with one's peers who are 'acting up' in the classroom can be overwhelming. If you 
are brave enough to go against this and engage with high school education, falling in to what Brown (1987) would describe as a 'positive', you run the risk of being branded a 'geek' or a 'muppet'. Nowadays such terms are used to describe young people who are 'good' at school, and bullying is often a consequence of these labels (MacDonald \& Marsh, 2005).

With teaching becoming an increasingly female dominated profession (Epstein et al., 1998) a lack of male role models within the education system is a consequence.

After all, it is a common view that 'if a boy does not have a community of men, then he is likely to look elsewhere for his role models' (Sax, 2007, p170). A participant in a 1994 study summed this up by saying:

The male teachers were nothing like my father and the female ones nothing like my mother, or any other relatives, come to that' (Bourke, 1994, p121).

The argument that working-class boys struggle to relate to teachers may be relevant, although there could be additional or new aspects to consider in contemporary Britain. This is an area in which, arguably, there is a gap in the literature. One concern could be that many professionals have little understanding as to what 'type' of male the working-class boys of today would see as potential role models. The idea that working-class boys see teachers as role models could be far from reality.

A new idea, and one which cannot be ignored in $21^{\text {st }}$ century Britain, is that for many working-class young men, appearance matters. We live in a capitalist society and as a result, an extremely materialistic culture has developed amongst many young people, the pressures of which may be intensifying. It therefore cannot be ignored as many working-class young men judge people simply by the brand of footwear or clothing they wear. Consequently, whether or not a person is wearing the clothing they desire, or wear themselves, could now be a barrier towards the development of positive relationships between teachers and working class boys. This is an especially important point as there is no evidence to suggest that the education system currently recognises this as an issue. This could be linked to what Sax (2007) describes as the widening gap between generations, which is a cause for concern.

\section{Research Aims}

- To explore the attitudes disengaged working-class boys have towards education

- To establish contributing factors towards disengagement

- To identify what working-class boys aspire to

- To allow space for barriers towards engagement with education to be identified.

Out of these aims came the following:-

\section{Research Questions}

1. What are the current attitudes of working-class boys towards education?

2. What are the barriers to learning and positive engagement within schools and pupil referral units from their perspective?

3. What do working-class young men aspire to? 
In an attempt to answer these research questions, the chosen strategy was a survey, with a mixed-methods approach (Denscombe, 2010), made up of a selected sample of working-class males of high school age currently being educated in the city. The research methods used were questionnaires and semi-structured interviews.

\section{Research Methods}

As the research participants were young men disengaging from education, consideration was given to the likelihood of low participation in the questionnaire survey, particularly concerning the use of open questions. Whilst one advantage with open questioning is that they are more 'likely to reflect the full richness and complexity of the views held by the respondent' (Denscombe, 2010, p165), a disadvantage is that greater effort, thought and time is required by the respondents (Denscombe, 2010). This increases the risk of a lack of engagement from participants, although the respondent's familiarity with the researcher reduced this. A small-scale research study (Cochrane, Brenda \& Jones, 2010) is comparable to this study as the researcher successfully used existing relationships with participants as a tool when collecting data. It was suggested that having being previously acquainted, participants felt able to talk honestly.

The use of closed questions within a questionnaire to gather the majority of data in a social science research project may seem limited as 'closed questions, in general, lend themselves to the production of quantitative data' (Denscombe, 2010, p166). These, though, were the main focus in an attempt to gain a picture of the challenges participants faced throughout their education. It is impossible to interpret the findings as facts as questionnaires gather personal thought and opinion at a particular time, however the data is consistent as participants answered identical questions, and as a result, reliability is improved, providing standardised data (Denscombe, 2010).

\section{Sample}

The chosen sample was comprised of 23 young men who resided in the city and were currently being educated in state schools, academies or pupil referral units. The participants were young men who had previously been referred to an external organisation for 1:1 intervention work by high schools and pupil referral units, being identified as disengaging or disengaged from education. This ensured that the research was relevant and with education settings having already identified these young people, the sample was consistent and provided data that was representative of the group in question (Walliman \& Buckler, 2008). The fact that the sample was made up of young men of appropriate age, from a range of mainstream schools and pupil referral units throughout the city, enhances dependability. The use of triangulation by cross referencing data sets from various educational settings, as well as adopting a mixed-method approach, further enhances the reliability of the research. The settings in which the research was conducted included educational settings, youth centres, and participant's homes, ensuring respondents felt as comfortable as possible during the research process. All the research undertaken underwent ethical review, which was approved by the University of Huddersfield.

\section{Research analysis}

The data was analysed using coding and presented using a combination of description, explanation and interpretation (Denscombe, 2010). The findings show, to some extent, what was expected in terms of establishing the potential barriers to 
learning from the perspective of working-class boys. Surprisingly though, some participants enjoyed being at school on the whole. 19 of the 23 participants identified as white British, with 2 identifying as black Caribbean and 2 as mixed white/black Caribbean. 17 participants were currently being educated within mainstream schools in the city, with the remaining 6 at a PRU. Given the nature of the responses, some of the data was quantifiable and themes were evident, which offered some answers to the research questions (Densombe, 2010). These themes are presented in the form of bar charts in an attempt to improve clarity and will be discussed throughout the rest of the paper (Denscombe, 2010). The qualitative data collected was coded, linked with these themes and interwoven throughout the analysis.

\section{Social Class}

In terms of identifying the participant's social class, each young person completed the BBC's (2013) test. The BBC (2013) conducted a study aimed at analysing the modern British class system and argues that defining class by occupation, wealth and education is now too simplistic. This research included measuring economic capital in terms of income, savings and property value, as well as social capital, including the number and status of people a person knows. The study also measured cultural capital, defined in this case as the extent and nature of cultural interests and activities. As a result, a new model made up of seven groups was established. Figure 1 shows which of the BBC's identified class groups the 23 participants fell in to. As discussed in the literature review, these two class groups represented are the lowest of the seven identified by the BBC (2013) and could also be placed in to a broader 'working-class' category, along with the BBC's other identified traditional workingclass and new affluent workers class groups.

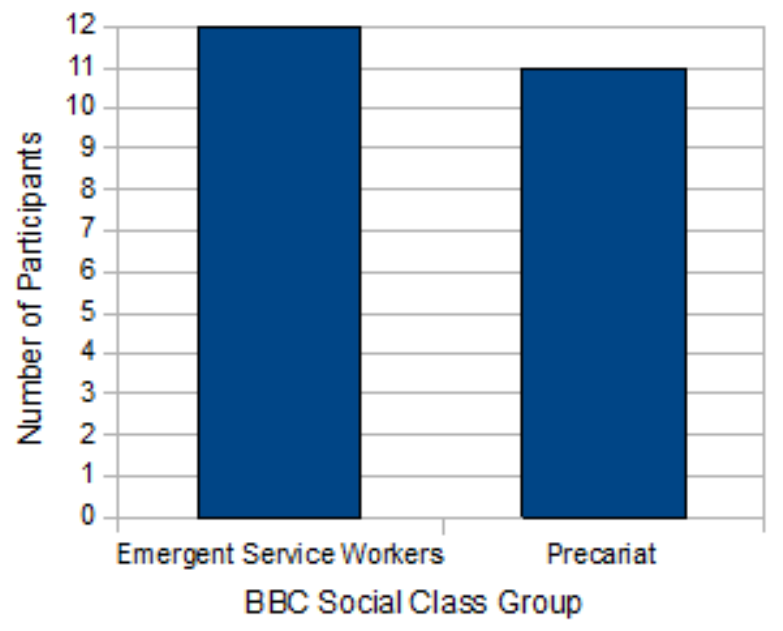

Figure 1. BBC Social class

The BBC (2013) identifies the 'emergent service workers' class group as a new young urban group who do not have much money but tend to 'live for today'. The 'precariat' group is described as the poorest, most deprived class group, who score low economically, socially and culturally. If one was sceptical about the methods used to identify class, or the creditability of the BBC's (2013) test, Figure 2 contains an overview of the parental occupations of the participants. 


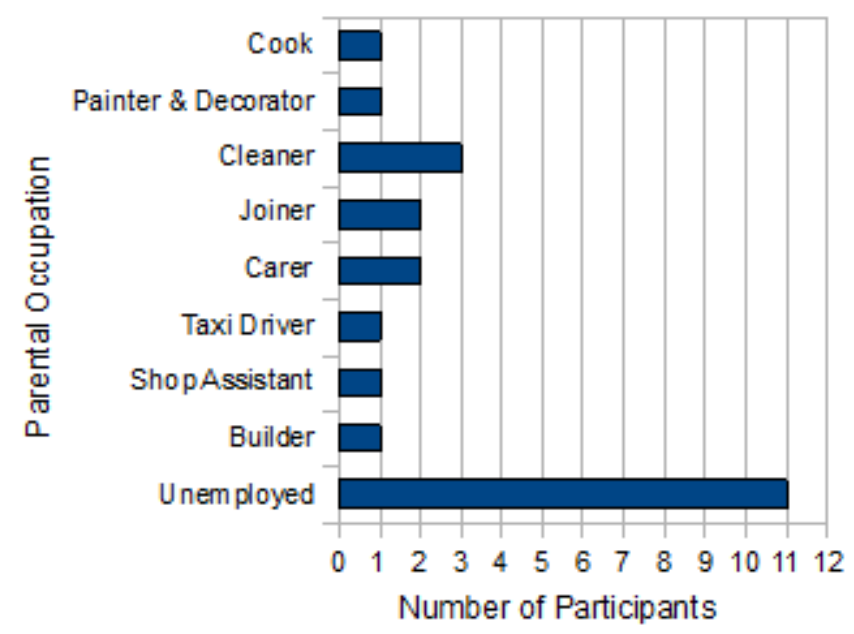

Figure 2. Parental occupation of participants

If the 'Occupational Scale', used to identify social class in the 2011 census (Roberts, 2011), is utilised, then a similar conclusion is reached. Using either measure, the young men who participated in the research for this study, were working-class, echoing Roberts' (2011) and Breen \& Rottman's (1995) ideas, suggesting that class is still relevant in contemporary society.

\section{Aspirations}

Two questions about working-class boys' aspirations were asked.

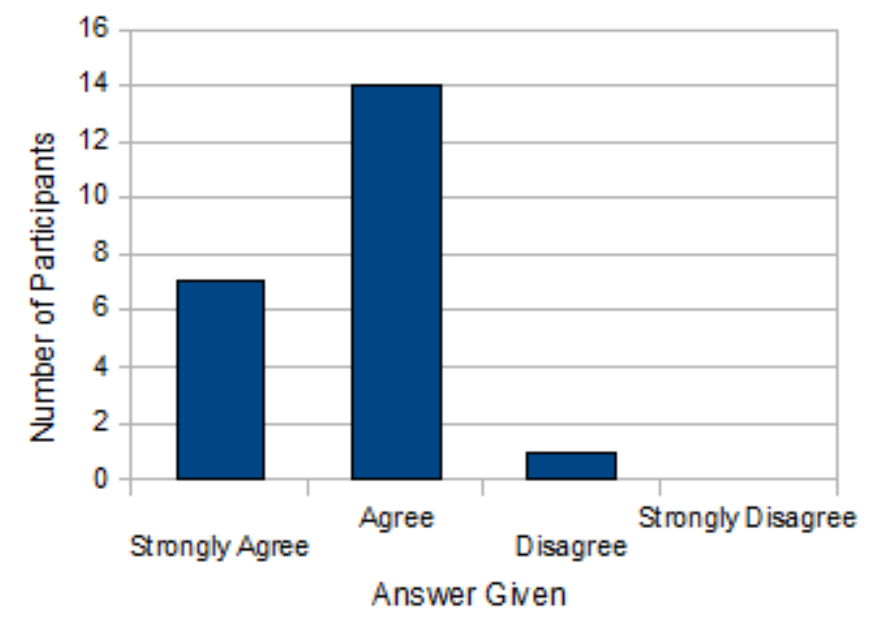

Figure 3. I want to get a job in the future

The results show that the participants aspired to gain employment after they finished in education (see Figure 3). With 48 percent of the participants representative of the BBC's (2013) 'precariat' or social class group located at the bottom, they would be members of the group Charles Murray (1994) contentiously described as the 'underclass'. Whilst this sample is relatively small, these results certainly suggest that claims that many young men have little or no aspiration to work is a myth; and suggests that participants are 'not so much stable members of the underclass, as unstable members of the working class' (Buck, 1992, p19). This is further supported by comments from the interviewee who responded when questioned about his aspirations by saying 'I would like to do a job that I liked and was hands on' (see 
appendix 7). The data collected from the second question asked about aspirations is shown below (Figure 4).

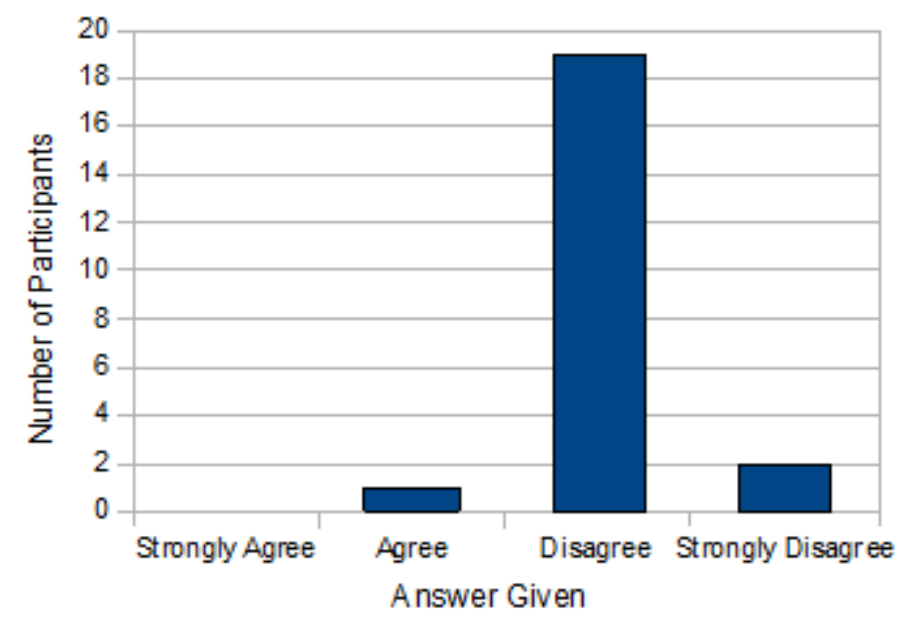

Figure 4. After I leave school want to go to university

At the time of completing the questionnaire, 95 percent of the participants had no desire to progress in to higher education. These results would offer support to Jackson and Marsden's (1966) conclusions which suggested that working-class young people disengaged from education primarily because they wanted to enter the labour market as soon as possible. Fanon's (1961) ideas around consciousness could also be used to interpret these results. If working-class young men internalise the thought that university is out of their reach, or do not associate it with something that people 'like them' pursue, then it is probably unlikely that they will aspire to enter higher education. With the collapse of the traditional youth labour market (Simmons \& Thompson, 2013) it means that these findings could be deeply problematic, especially if reflected nationally. Previously, 'educational policy failed to convince working-class parents that education was the key to upward social mobility' (Bourke, 1994, p120), and these results suggest that it could still be the case in this city today.

\section{Behaviour as a barrier to learning}

Results from questions about participants' views on potential barriers to learning and positive engagement in education are shown in Figure 5 and 6 . This data shows that the vast majority of participants self-identified as displaying poor behaviour in school, whilst also demonstrating an understanding that teachers would recognise or class this behaviour as poor. This behaviour would most certainly act as a barrier to learning and engagement with school and the results certainly go some way to supporting the national statistic, that in 2007, boys accounted for three quarters of fixed-term exclusions, and 80 percent of permanent exclusions (DfES 2007). 


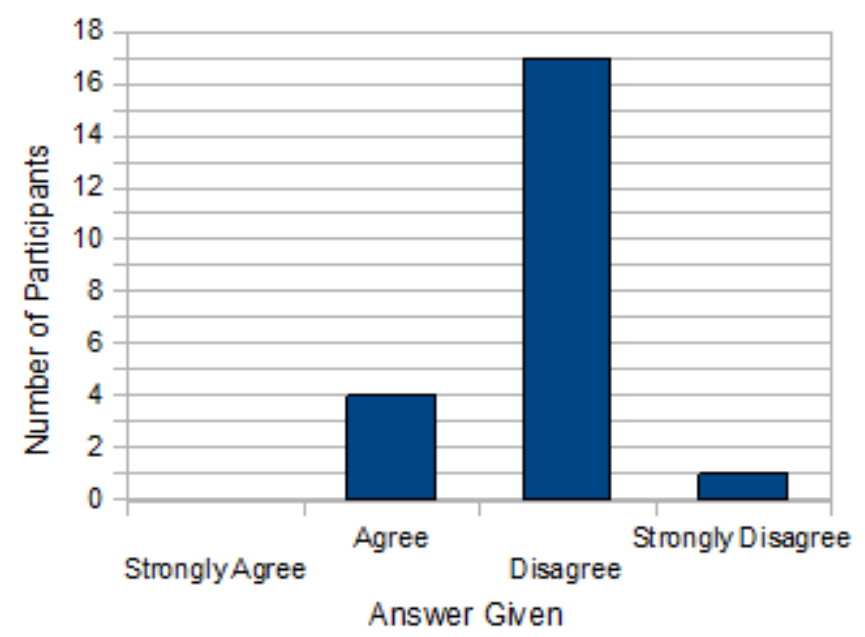

Figure 5. My general behaviour in school is good

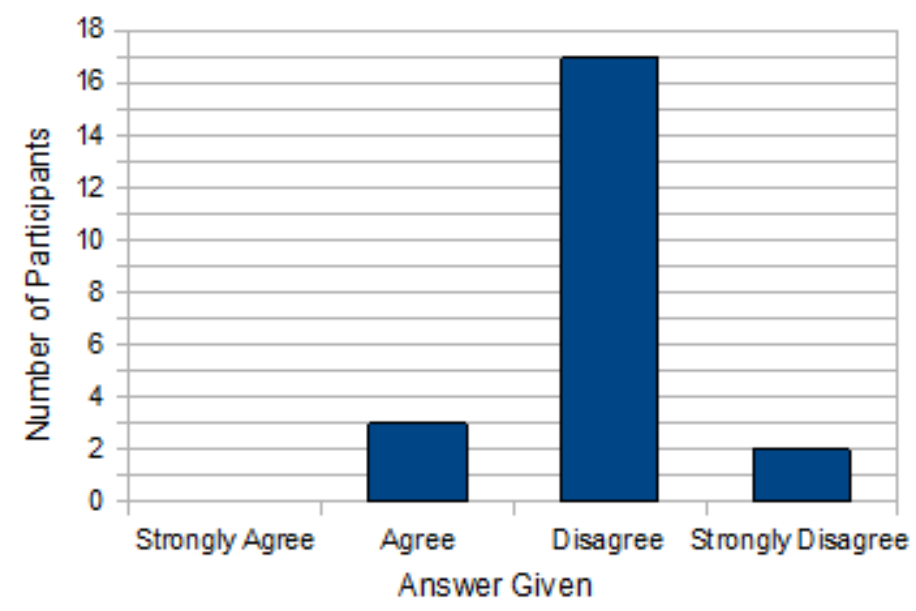

Figure 6. My teachers would say my behaviour in school is good

The answers given by the interviewee suggests that this poor behaviour is displayed in response to being treated unfairly by teachers.

I: How would you describe your general behaviour in school? And what are the reasons for this behaviour?

$P$ : I don't think it's that bad, I just think it is when you get put in a certain situation where you feel as if you have to say something about what's going on.

I: Go on, what do you mean by that? A certain situation by whom?

$P$ : Like teachers. They try to put you on the spot and make you feel uncomfortable about what's happening in front of all your other pupils, like try and show you up by making their sarcastic comments. You could say it's bad because of the attitude but it's not. If I come across in the right way you would get it. 
A useful theory that could be used in an attempt to explain this poor behaviour, in relation to this city in particular, is MacDonald \& Marsh's (2005) idea around schools focusing their resources on the pupils most likely to achieve academic success due to the demand for improvement by Ofsted. Table 1 shows that the academic attainment of young people in this city is below average.

\begin{tabular}{|c|c|c|c|c|}
\hline Variable & Measure & $\begin{array}{c}\text { City were } \\
\text { research } \\
\text { carried out }\end{array}$ & North West & England \\
\hline $\begin{array}{c}\text { Pupils Achieving } \\
5+\text { A* C GCSEs } \\
\text { or Equivalent, } \\
\text { Including English } \\
\text { and Mathematics } \\
\text { (Persons, Sep11- } \\
\text { Aug12) }\end{array}$ & $\%$ & 54.5 & 58.9 & 58.8 \\
\hline $\begin{array}{c}\text { Unemployment } \\
\text { Rate; Aged 16-64 } \\
\text { (Persons, Apr12- } \\
\text { Mar13) }\end{array}$ & $\%$ & 10.5 & 8.3 & 7.8 \\
\hline
\end{tabular}

Table 1. Academic attainment of young people (Source: ONS, 2014)

With Ofsted publishing a report in 2013 about the standard of education in this local authority, resulting in a call for improvement, this could have damaging effects on these already underachieving working-class boys (DfE, 2014). As highlighted in the literature review, resources could then be employed elsewhere and working-class boys could be failing to receive the required support that would enable them to achieve. Unsurprisingly, Colley \& Hodkinson (2001) argue that when this occurs, the socially excluded group become disillusioned and rebel, reflected in the poor behaviour displayed by the majority of participants of this study. The responses in Figure 7 could also link into the idea of working-class young men 'rebelling'.

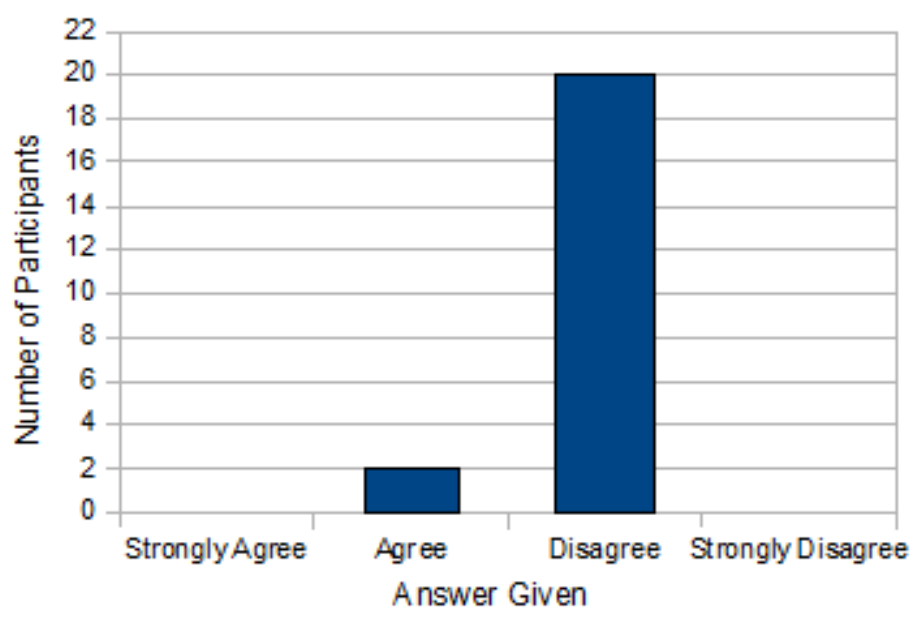

Figure 7. I try as hard as I can in school 
These results also support Burns \& Bracey's (2001) theory about the culture within working-class environments, concerned with the lack of encouragement given to boys to apply themselves at school. As Wilson and Pickett (2010, p115) note:

While education is viewed by the middle class and by teachers and policy makers as the way upwards and outwards for the poor and working class, these values are not always subscribed to by the poor and working class themselves.

Whilst this was perhaps not as important when there were considerable employment opportunities for working-class young men leaving school, it has become a problem that will continue to escalate.

\section{Pupil/Teacher relationships as a barrier}

The following questions were asked in an attempt to gain an understanding about whether teacher/pupil relationships act as a barrier to educational engagement. These findings are presented in figures 8 and 9.

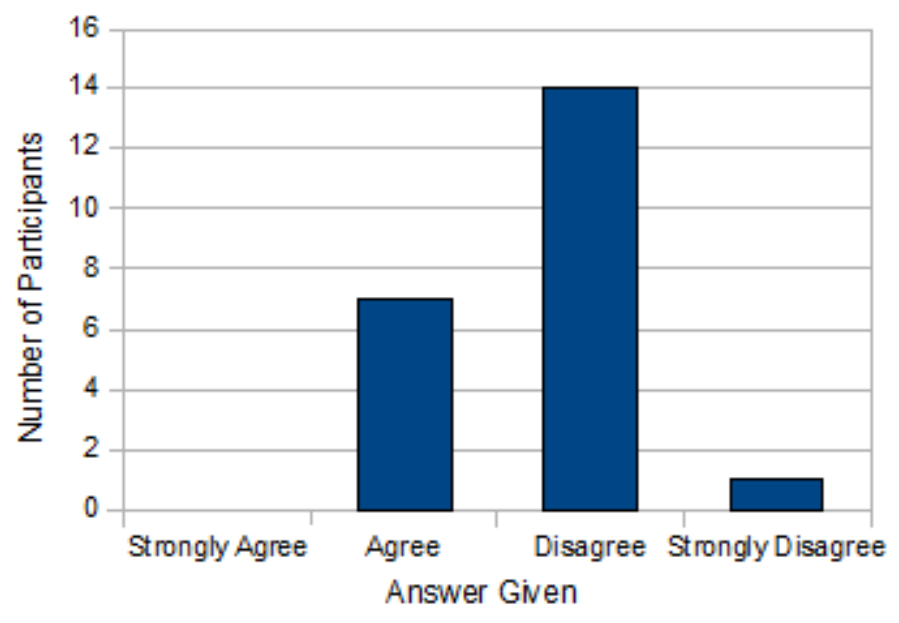

Figure 8. Teachers listen to me

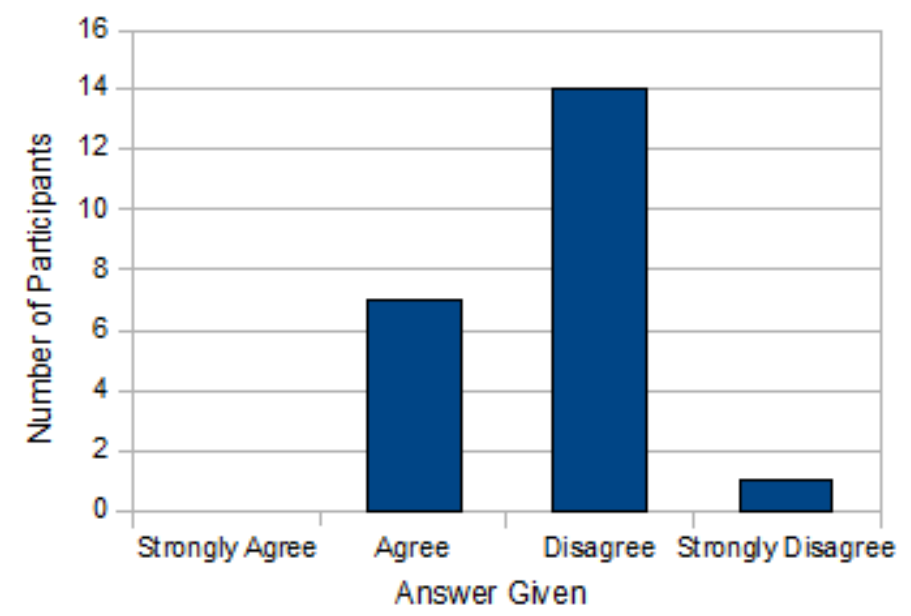

Figure 9. Teachers treat me fairly 
These two questions were particularly concerned with understanding how participants felt they were treated by teachers. It was hoped the results would offer some indication as to whether there was a perception that the participants felt that they were neither listened to, nor treated fairly by teachers: and as the results show, 68 percent of the participants felt this was the case. The findings also indicate that this could be a consequence of government policies such as Bridging the Gap (SEU, 1999), policies which have the potential to indirectly socially exclude working-class males not only within this city, but nationally. This would inevitably contribute to their perceived oppression, potentially causing them to disengage as a result. The following extract taken from the interview conducted supports this argument.

I: How would you describe your relationships with teachers and why?

$P$ : It depends what teachers, some teachers try and, like if you're ok with me then I'm never disrespectful or disrupt your lesson or anything but when teachers try and make a problem, that's where I come across as disrespectful and aggressive.

l: ...so do you feel like teachers treat you fairly?

P: No, not all the time.

I: And do you feel like teachers respect you?

$P$ : It depends on which teacher it is; because some of them will just, you know, already have their opinion on you and wont, or they will have you down as something before they even know you.

Although the qualitative data presented enriches the quantitative data regarding this issue, and certainly emphasises that this is indeed an idea worth engaging with, it could be argued that because 32 percent of the participants expressed that they felt teachers did listen to them and treated them fairly this shows that this cannot be considered a barrier to engagement in isolation. Within the theme of teacher/pupil relationships, whether the participants felt like they could relate to teachers needed to be explored. Figure 10 and 11 outline the questions asked and the responses.

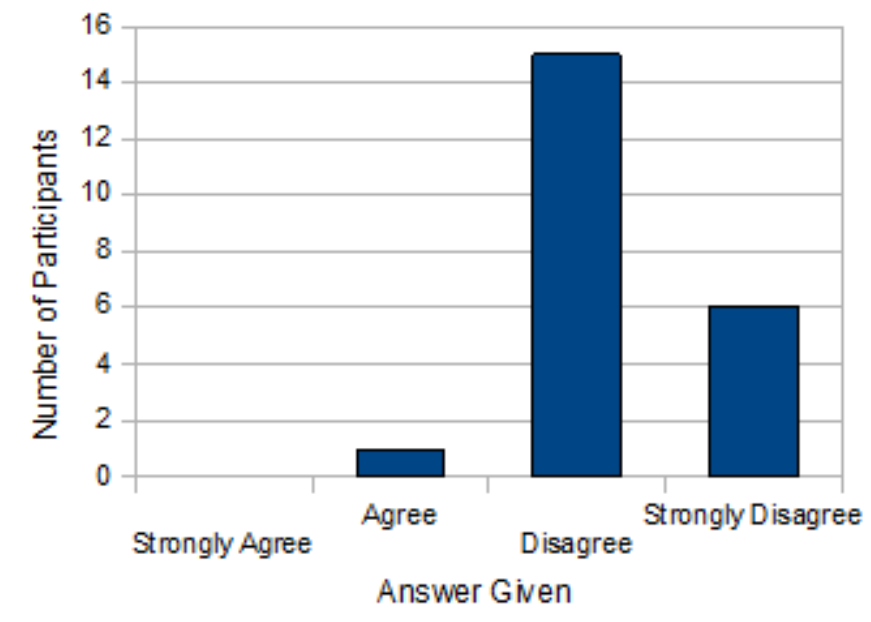

Figure 10. Teachers are people who are similar to me 


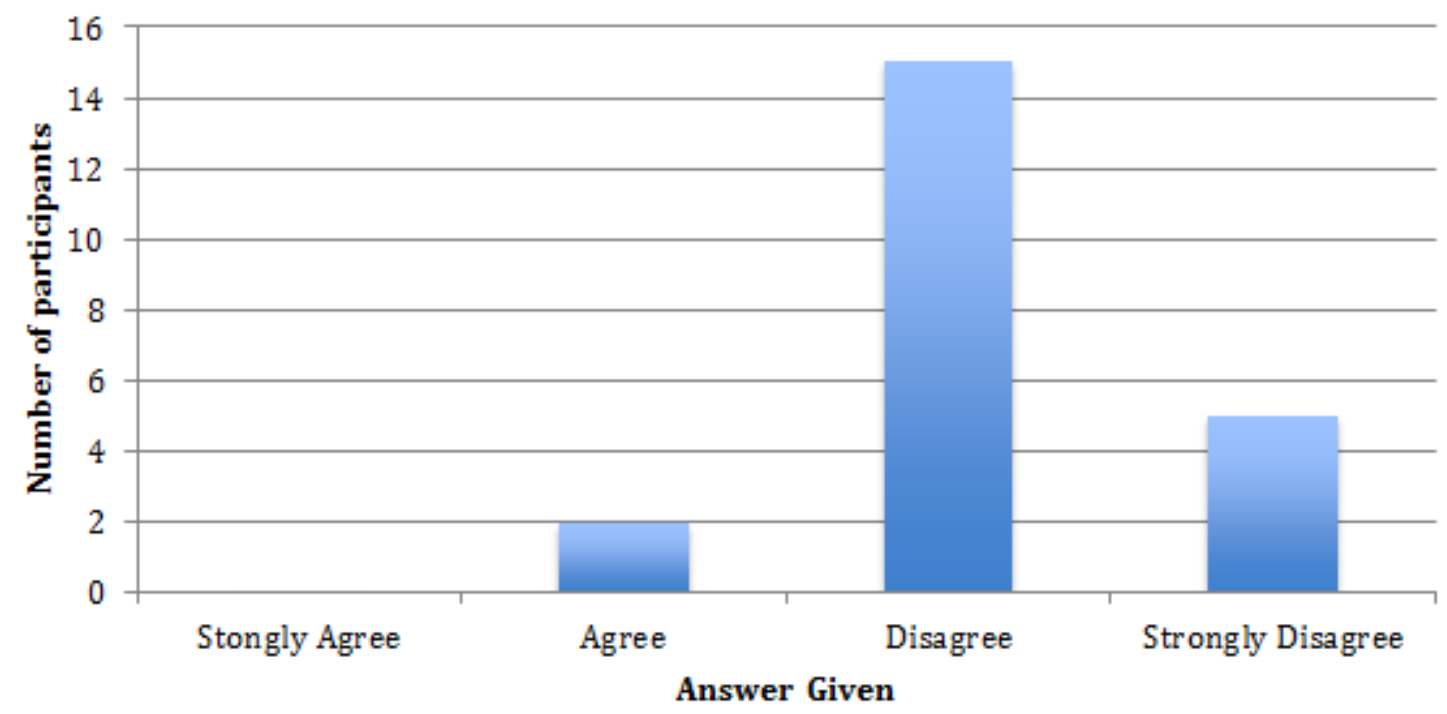

Figure 11. My teachers understand what it's like growing up in this area

These findings reflect the argument that working-class males do not see teachers as role models. The results overwhelmingly acknowledge this, with 95 percent of the participants having the opinion that teachers are not similar to them. In addition, 91 percent also felt that teachers did not understand what it was like to grow up in area, another question which could be attributed to the problem working-class boys have with relating to teachers. Although these findings only relate to a small sample of working-class boys within a particular city, they do indicate that this is an idea worthy of further exploration. Bourke's (1994) claims about working-class boys struggling to relate to the male teachers are particularly relevant. In the interview the young man responded with, 'no, not at all' when asked whether he can relate to teachers and whether they are similar to him. When asked to expand on this, the participant added:

Because they just, they have got no, just look at them, they don't have, like they don't think about what's going on, they just think they know, they don't have the same problems.

These comments also support Sax's (2007) concerns about with the widening gap between the generations.

\section{Attitudes to Curriculum \& Education System}

In an attempt to establish whether or not the education system and the content of the national curriculum affected educational disengagement, four questions were asked. Before the results are presented, comments were made by the participants that relate to these themes. One respondent wrote 'school is shit and they teach pointless stuff'. Another wrote 'when the teacher comes in the room you have to stand up, it's fucking daft'. Willis' (1977) argument that working-class boys reject the middle-class values entrenched within the education system could go some way to explain the latter comment. Figure 12 clearly shows that 100 percent of the participants claimed to get bored in lessons. 


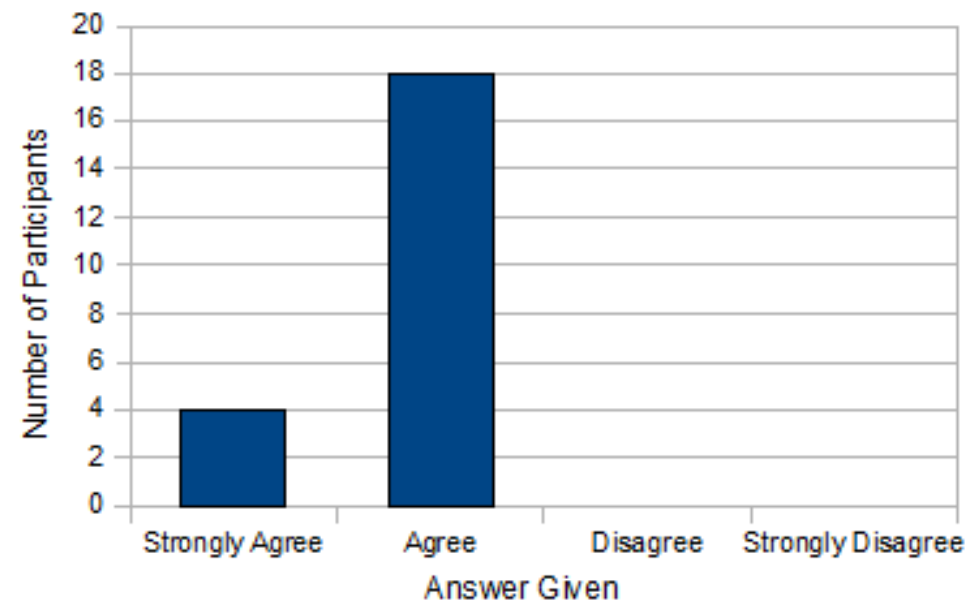

Figure 12. I normally get bored in lessons

This links closely with Paulo Freire's (1996) argument concerning individual's disengagement from education if the curriculum is not relevant to their situation. The findings in the table below offer further support to this viewpoint with 77 percent of the participants disagreeing with the suggestion that the work they do in school interests them.

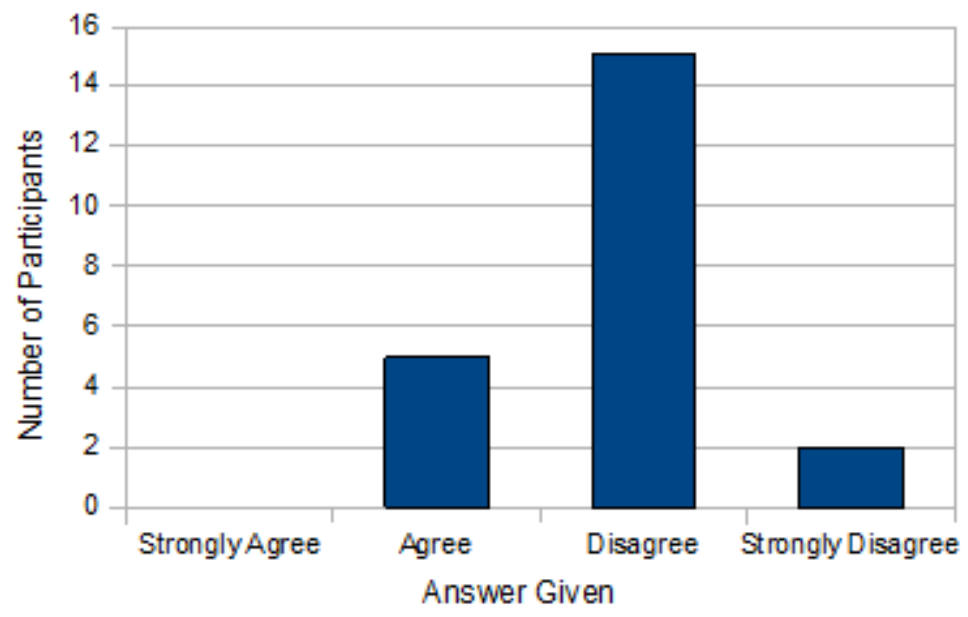

Figure 13. The work done in lessons is interesting

When asked to offer his thoughts on the content of the work covered in lessons, the interviewee responded as follows:

I don't think it's important, it's not, it doesn't help you with anything. Like in history when do we really need to know when Queen Elizabeth was born when will we be going for that job?.

This quotation supports the findings presented in Figure 13, whilst offering a link to the results presented in Figure 14. 


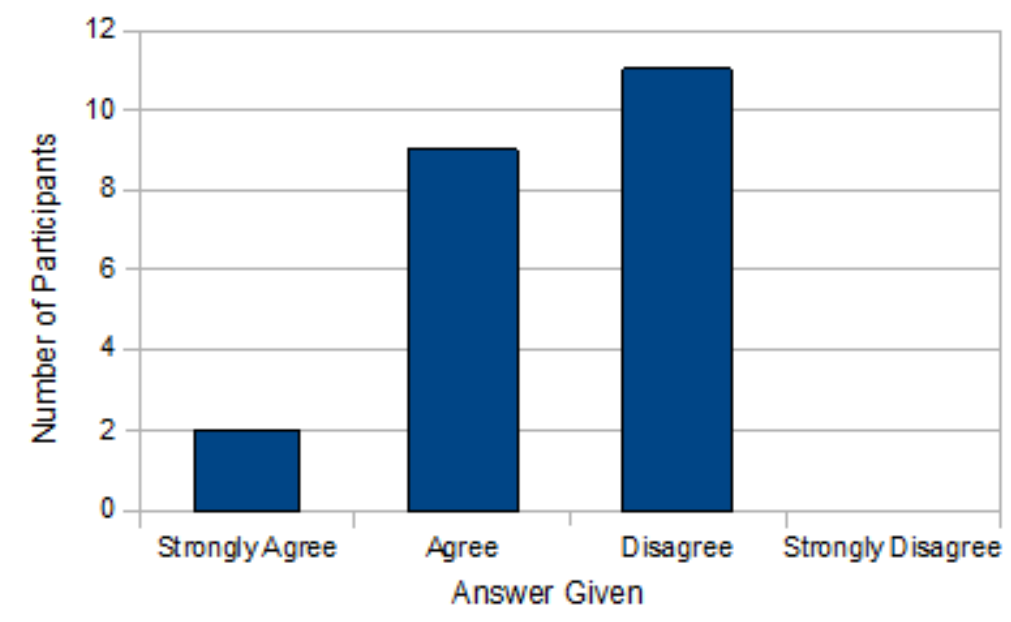

Figure 14. The work we do in lessons is a waste of time

If a chart was used to present the findings from the more generic question about whether participants saw school as a waste of time, the results would be identical with the Figure 14. Surprisingly, though, a slight majority of participants were of the opinion that the work in lessons is not a waste of time, as well as school as a whole. This seems to conflict with Bourke's findings that 'working-class respondents felt that education was theoretical and had little practical bearing on everyday life' (Bourke, 1994, p120). A comment made by one participant stated that 'school will help me in the future but I don't like going. I only done education in jail to get me out of my pad', supporting the majority in terms of this particular idea. Bourke's (1994) study was conducted 20 years ago, so the shift may be understandable, although the following data would indicate that Bourke's ideas are indeed still relevant today.

I: So you don't think the work you do in lessons is going to help you in life?.

P: No not really. They teach you about things that they think are important... they are not like us, they didn't really make the day what it is today.

So, whilst the overwhelming majority of participants disagreed or strongly disagreed with the idea that lessons are interesting, they were split when asked whether or not it was a waste of time. When analysed with the qualitative data one could arguably come to the conclusion that whilst respondents did not see education as necessarily relevant to a desired profession, they are beginning to see that it is required as a stepping stone to get them to where they want to be in terms of employment. Again, it is important to note that the sample was a small one, so these findings cannot claim to apply nationally, or even to the majority of working-class boys in Salford.

\section{Attitudes to school}

Three questions were asked to gain an insight in to the attitudes of working-class boys towards education. The data is presented in Figure 15. 


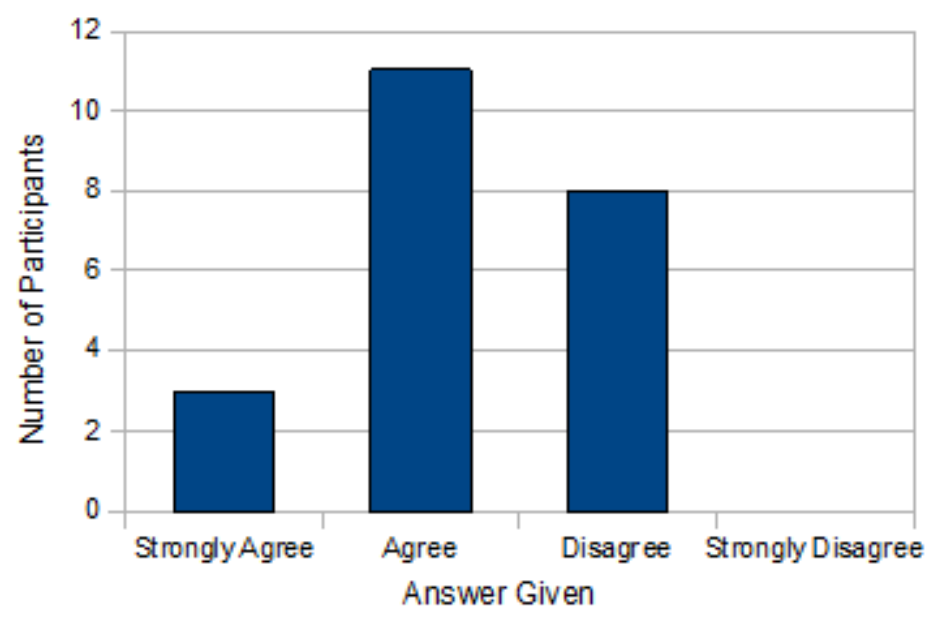

Figure 15. Most of the time I don't want to go to school

These results show that 64 percent of the participants felt like they did not want to go to school most of the time and an additional comment made was 'school is shit but I have to go'.

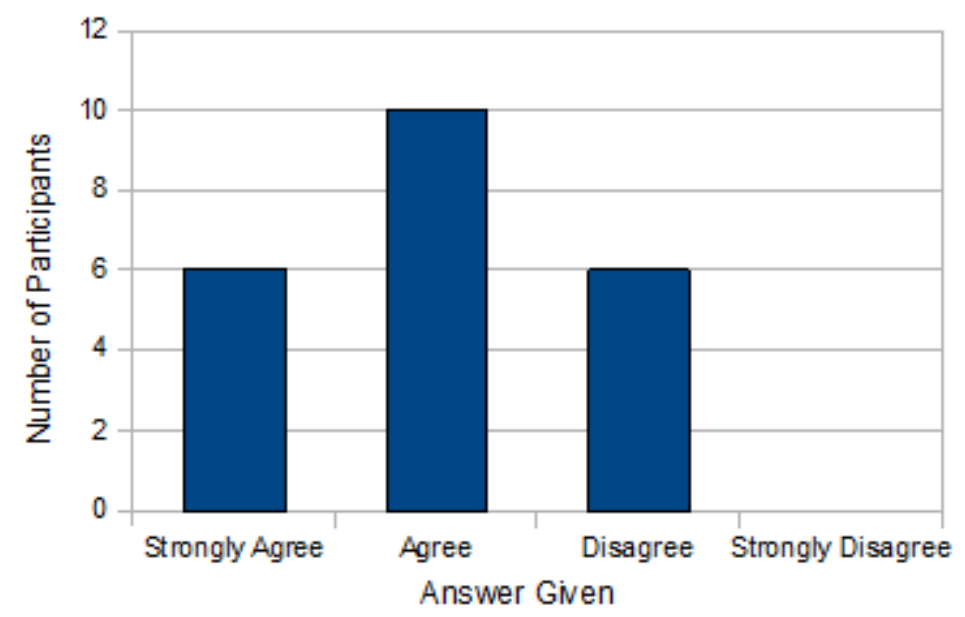

Figure 16. If I didn't have to go in to school I wouldn't bother

73 percent of the participants said they would not go to school if they did not have to (see Figure 16). Although this percentage is high, it arguably says little about educational disengagement. If people were asked whether they would go to work if they did not have to, then the results could be similar. This would not mean that people who did not want to go to work would necessarily disengage with work as a result, although the factor of age must be considered when making comparisons between school and work. 


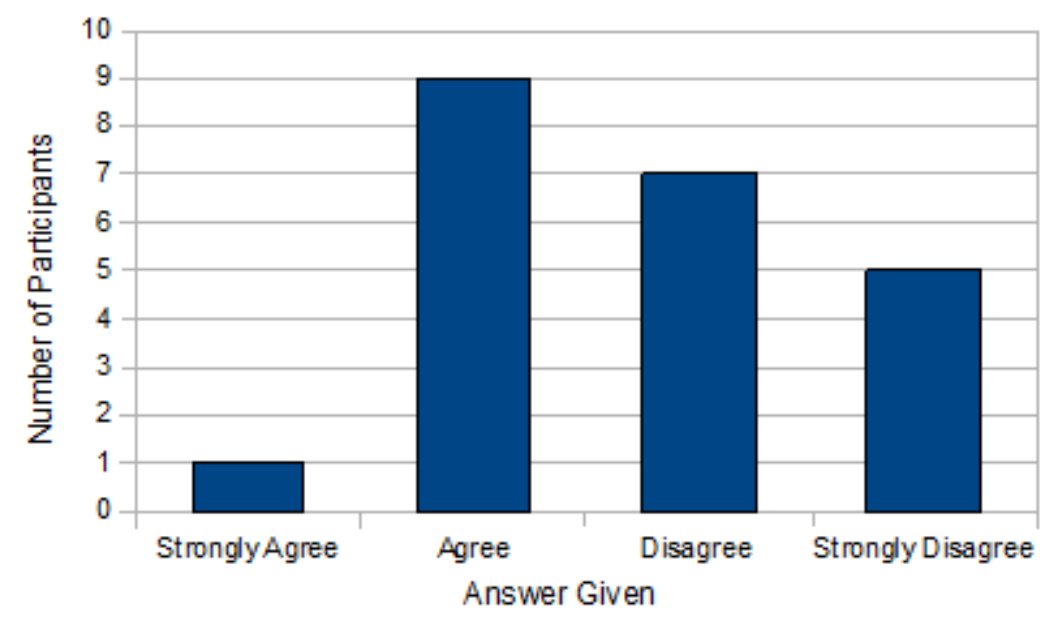

Figure 17. Overall, I like being at school

The results shown in Figure 17 indicate a split amongst the participants in terms of whether the liked being at school on the whole. Interestingly, 54 percent indicated that they did not, 46 percent suggested that they did with the extract below, taken from the interview, offering more insight.

I: Can you briefly describe some of the things that you like about school?.

$\mathrm{P}$ : I like going in in a morning and going into lessons and being with my friends.

I: So anything else?.

$\mathrm{P}$ : I like going into a lesson with a good teacher when you are actually learning stuff, because it's decent.

I: Okay can you describe some of the things that you don't like about school?.

P: I don't like the way that teachers can do something that you can't, and it's like its normal.

I: What do you mean do something that you can't?.

$\mathrm{P}$ : Like they can make a sarcastic comment to you and nothing is said about it but when you do one to them then there will be a consequence.

These results emphasise a recurring theme, which has been evident throughout, that educational disengagement is a result of negative relationships between teachers and pupils, at least from the perspective of these working-class boys. 


\section{Alternate Factors}

Participants were asked the question below (Figure 18), which on reflection, was perhaps too vague.

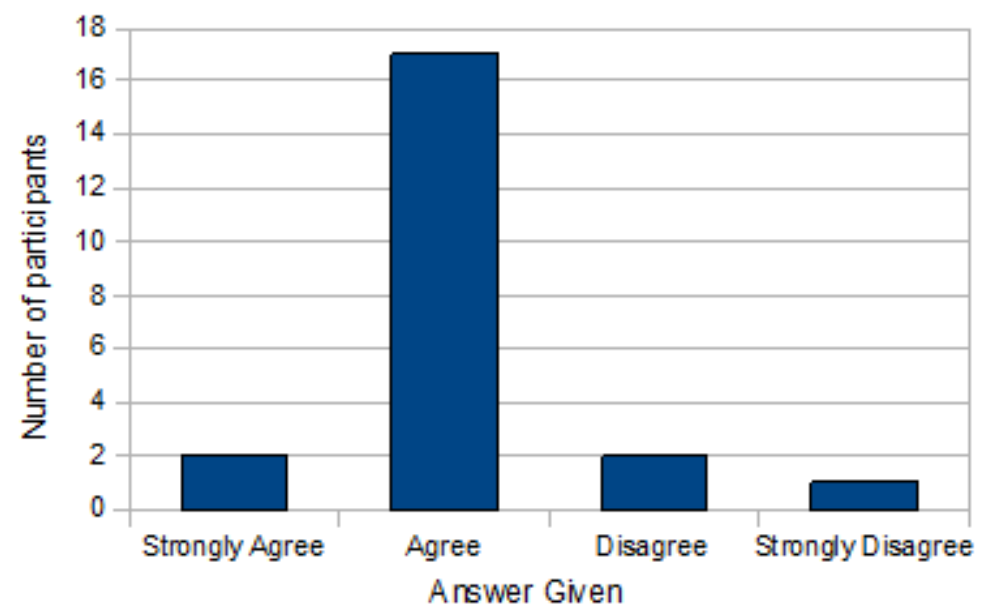

Figure 18. I have more important things to worry about than school

With 77 percent of the participants claiming to have more important things to worry about than school, the percentage of participants eligible for free school meals (FSM) may offer some indication as to what these more important things may consist of. The DfE (2012) indicates that those eligible for FSM are living in deprived circumstances. 43 percent of respondents indicated that they claimed FSM. In a government paper which explored FSM, it was concluded that at least 14 percent of the pupils entitled to FSM are not actually claiming them (DfE, 2012). In 2013, 37.9 percent of pupils who qualified for FSM got 5 GCSEs compared with 64.6 percent of those who did not qualify (DfE, 2014). This demonstrates the impact that deprivation may have on educational disengagement. Ivan Illich $(1996, p 6)$ argued that

'It should be obvious that even with schools of equal quality a poor child can seldom catch up with a rich one. Even if they attend equal schools and begin at the same age, poor children lack most of the educational opportunities which are casually available to the middle-class child so the poorer student will generally fall behind so long as he depends on the school for advancement or learning'.

\section{Findings}

The findings offer a critical insight in to some of the factors affecting working-class boys' engagement with education in this city, suggesting that there are a combination of factors, including deprivation (DfE, 2012), an inappropriate curriculum for certain groups, as well as an education system which is not truly inclusive of everyone (Illich, 1996). Perhaps the most significant barrier identified, however, was the pupil/teacher relationship, particularly concerning the issue of 'relate-ability'.

\section{Conclusion}

This study has identified some of the factors contributing towards educational disengagement of working-class boys in this city, alongside some potential barriers towards learning. It also uncovered the aspirations this particular group have for their futures, a crucial insight in the attempt to answer the research questions. The 
findings indicated that there are a number of factors, as suggested by Sax (2007), which impact on their disengagement from education. The education system, including the national curriculum as well as government policy, affects young people and it is important to recognise that 'educational disadvantage cannot be cured by relying on education within the school' (Illich, 1996, p5). Other factors, including deprivation, have the potential to increase the risk of disengagement. Findings from this study put a strong emphasis on the negative relationships between workingclass young men and their teachers. The fact that appearance alone could now be an issue for working-class boys cannot be ignored.

Statistics clearly demonstrate the magnitude of the problem as certain boys continue to underachieve (DfE, 2014), especially those from low-income families (Ofsted 2103). If concerns about the levels of educational engagement in relation to this particular city as a local authority (Ofsted, 2013) are also taken into consideration, then it could be concluded that this specific group of young men from the city are of particular concern. If the situation is to improve, 'it is important to recognise the gendered nature of society because it is a major source of social identity' (Billington, Hockey \& Strawbridge, 1998, p27) and that, to a large extent, social structures, class in this case, are more important in influencing peoples' lives than individual characteristics (Taylor et al., 2001). This means discussing the role of gender alongside other variables such as ethnicity and social class ensures that the focus is not solely on the concept of the 'gender gap' in education.

In terms of offering ways forward, schools must look at employing members of staff, whether this is teachers, mentors, or any kind of support staff to whom pupils can relate. It is fundamental that this process is carried out with input from young people, as their idea of potential role models can differ from that of a professional. Illich's (1996) suggestion that 'at best, a small fraction of each dollar intended to remedy a poor child's disadvantages in learning could reach the child through the school budget' (Illich, 1996, p6) is surely relevant in Britain today. The pupil premium (DfE, 2014) needs to find its way to the pupils it is intended to 'help' if the position of working-class boys is to improve. Importantly:

The fact is that boys now leaving these schools, unlike their fathers, encounter the situation where there are no jobs for life. By raising boys' awareness of the situation that faces them, the schools may well help boys to recognise the importance of their education and give them added motivation to succeed.

(Burns \& Bracey, 2001, p155)

Careful consideration that this could potentially demotivate them most be given, however with effective methods, this could be the way to move forward.

A review of the national curriculum with a shift towards 'education focusing on the process of learning, rather than swathes of imminently outdated content and a focus on satisfaction with "being" rather than "having"' (Coates, 2010, p112) is something that is desperately required, although unlikely to happen within the current neoliberal thinking of today. After all, 'the biggest influence on educational attainment, how well a child performs in school and later in higher education, is family background' (Wilkinson \& Pickett, 2010, p103). These families, though, are impacted 
by the Coalition Government still implementing policies that 'hit the poor the hardest' (Dean, 2013), so, sadly, the challenge is becoming even more difficult as inequality continues to widen in $21^{\text {st }}$ Century Britain.

\section{References}

BBC (2013) The Great British Class Survey [Online] Available at: http://www.bbc.co.uk/news/uk-22007058 [Accessed 21.04.2014]

Beinart S, Anderson B, Lee S and Utting D. (2002) Youth at Risk? A national survey of risk factors, protective factors and problem behaviour among young people in England, Scotland and Wales. London: Communities that Care.

BERA (2011) Ethical Guidelines for Educational Research [online] Available at http://www.bera.ac.uk/wp-content/uploads/2013/12/BERA-Ethical-Guidelines2011.pdf [Accessed 12.04.14]

Billington, R., Hockey, J. L., \& Strawbridge, S. (1998). Exploring Self and Society. Basingstoke: Macmillan

Bourke, J. (1994) Working class cultures in Britain 1890-1960: Gender, class and ethnicity. London: Routledge

Breen, R.and Rottman, D. (1995) Class Stratification. London: Harvester Wheatsheaf

Browne, K. and Mitsos, E. (1998) Gender differences in education: the underachievement of boys, Sociology Review, September, pp. 27-31.

Brown, P. (1987) Schooling Ordinary Kids. London: Tavistock

Buck, N. (1992) 'Labour market inactivity and polarisation', in Smith, D. (ed.), Understanding the Underclass, London: Policy Studies Institute

Burns, J., and Bracey, P. (2001). Boys' underachievement: Issues, challenges and possible ways forward. Westminster Studies in Education, 24(2), 155-166.

http://dx.doi.org/10.1080/01406720120069507

Cannadine, D. (2000) Class in Britain. London: Penguin

Coates, M. (2010) Future schools: Shaping a new educational landscape: Exploring possibilities for education in the 21st century. London: Continuum International Publishing

Cochrane, B. and Jones, H. M. F. (2010) Everybody else does it: Young British women, safety and risk. Commonwealth Youth and Development, 8 (1). pp. 37-55. Colley, H. and Hodkinson, P. (2001) Problems with bridging the gap: The reversal of structure and agency in addressing social exclusion [online] Available at http://csp.sagepub.com/content/21/3/335 [Accessed 28.04.14] 
Connolly, P. (2006) Keeping a sense of proportion but losing all perspective: A critique of Gorard's notion of the 'politician's error'. British Journal of Educational Studies, 54 (1), 73-88. http://dx.doi.org/10.1111/j.1467-8527.2005.00330.x

Cooper, J. (1979) Class. London: Eyre Methuen

Dean, M. (2013) Margaret Thatcher's policies hit the poor hardest - and it's happening again, Guardian. April 9 [Online] Available at http://www.guardian.co.uk/society/2013/apr/09/margaret-thatcher-policies-poorsociety?CMP=twt fd [Accessed 19.05.14]

Denscombe, M. (2010) The good research guide: For small-scale social research projects ( $4^{\text {th }}$ edition). McGraw-Hill Education: Open University Press

Department for Education and Skills [DfES] (2007) Gender and education: the evidence on pupils in England [Online] Available at www.dfes.gov.uk/research [Accessed 09.05.14]

Department for Education [DfE] (2012) Pupils not claiming free school meals [DfE] [Online] Available at https://www.gov.uk/government/uploads/system/uploads/attachment data/file/18338 0/DFE-RR235.pdf [Accessed 15.05.14]

Department for Education [DfE] (2014) G.C.S.E and equivalent attainment by pupil characteristics in England, 2012/13 [Online] Available at https://www.gov.uk/government/uploads/system/uploads/attachment data/file/28068 9/SFR05 2014 Text FINAL.pdf [Accessed 18.04.2014]

Department for Education [DfE] (2014) Pupil premium: funding for schools and alternative provision [Online] Available at https://www.gov.uk/pupil-premiuminformation-for-schools-and-alternative-provision-settings [Accessed 20.05.14]

Epstein, D. (1998) Failing Boys? Issues in gender and achievement. Buckingham: Open University Press

Fanon, F. (1961) The Wretched of the Earth. London: Penguin

Freire, P. (1996) Pedagogy of the oppressed. London: Penguin Books

Hanley, L. (2014) 'Thought class was dead? Read Richard Hoggart', Guardian. April 13 [Online] Available at http://www.theguardian.com/commentisfree/2014/apr/13/class-richard-hoggartsocial-media?CMP=twt gu [Accessed 18.04.14]

Hatcher, R. (1997) New Labour, school improvement and racial equality. Multicultural Teaching, 15 (3): 8-13

Home Office (1997) No More Excuses: A New Approach to Tackling Youth Crime in England and Wales. London: HMSO 
Hosie, A. C. S. (2007) 'I hated everything about school': An examination of the relationship between dislike of school, teenage pregnancy and educational disengagement. Social Policy \& Society 6:3, 333-347 http://dx.doi.org/10.1017/S1474746407003661

Illich, I. (1996) Deschooling Society. London: Marion Boyars Publishers Ltd

Jackson, B. and Marsden, D. (1966) Education and the working class: Some general themes raised by a study of 88 working class children in a northern industrial city. Harmondsworth: Penguin

Jackson, D. and Salisbury, J. (1996) Why should secondary schools take working with boys seriously? Gender \& Education, 8, pp. 103-115.

http://dx.doi.org/10.1080/713668477

Jones, O. (2012) (Revised edition) Chavs: The Demonisation of the Working Class. London: Verso Books

Levitas, R. (2005) The Inclusive Society? Social exclusion and new labour. Basingstoke: Palgrave Macmillan

MacDonald, R. (1997) Youth, the 'underclass' and social exclusion. New York: Routledge

MacDonald, R. and Marsh, J. (2005) Disconnected Youth? Growing Up in Britain's Poor Neighbourhoods. Basingstoke: Palgrave MacMillan

McIntosh, S. and Houghton, N. (2005) Disengagement from Secondary Education: A story retold. London: Learning and Skills Network

Murray, C. (1990) The Emerging British Underclass. London: IEA

Murray, C. (1994) The Underclass: The Crisis Deepens. London: IEA

Office for National Statistics [ONS] (2014) Neighbourhood Statistics [Online] Available at http://www.neighbourhood.statistics.gov.uk [Accessed 10.05.14]

Office for Standards in Education [Ofsted] (1997) From Failure to Success: How Special Measures are Helping Schools Improve. London: Ofsted

Office for Standards in Education [Ofsted] (2013) Ofsted Annual Report 2012/13: Schools [Online] Available at http://www.ofsted.gov.uk/resources/ofsted-annualreport-201213-schools [Accessed 09.05.14]

Roberts, K. (2011) Class in Contemporary Britain. Basingstoke: Palgrave MacMillan

Ross, A . (2009) Disengagement from Education among 14-16 year olds [Online] Available at https://www.gov.uk/government/uploads/system/uploads/attachment data/file/22199 2/DCSF-RR178.pdf [Accessed 28.04.14] 
Sax, L. (2007) Boys Adrift: The five factors driving the growing epidemic of unmotivated boys and underachieving young men. New York: Basic books

Simmons, R. and Thompson, R. (2013) Reclaiming the Disengaged: Critical Perspectives on Young People Not in Education, Employment or Training. Research in Post-Compulsory Education, 18 (1-2). pp. 1-11. http://dx.doi.org/10.1080/13596748.2013.755799

Simpson, D. and Cieslik, M. (2000) Expanding study support nationally: implications from an evaluation of the East Middlesbrough Education Action Zone's programme, Educational Studies, 26, 4, 503-15. http://dx.doi.org/10.1080/03055690020003674

Social Exclusion Unit [SEU] (1999) Bridging the Gap: New Opportunities for 16-18 Year Olds. London: HMSO

Taylor, P. et al. (2001) Sociology in Focus. Ormskirk: Causeway Press

Thomas, G. (2009) How to do your Research Project: A Guide for Students in Education and Applied Social Sciences. London: SAGE Publications Ltd

Walliman, N. S. R. and Buckler, S. (2008) Your Dissertation in Education. London: SAGE

Wilkinson, R. G. and Pickett, K. (2010) The Spirit Level: Why Equality is Better for Everyone. London: Penguin

Willis, P. (1977) Learning to Labour: How Working Class Kids Get Working Class Jobs. London: Saxon House 